\title{
Análise dos gols do campeonato brasileiro de futebol feminino 2020
}

\author{
Analysis of the goals of the brazilian women's football championship 2020 \\ Análisis de los goles del campeonato brasileño de fútbol femenino 2020
}

\author{
André Leon Lemos Pereira \\ ORCID: https://orcid.org/0000-0002-4208-8050 \\ Universidade Federal de Sergipe, Brasil \\ E-mail: andreleon056@gmail.com \\ Marcelo de Castro Haiachi \\ ORCID: https://orcid.org/0000-0002-9361-9018 \\ Universidade Federal de Sergipe, Brasil \\ E-mail: haiachi@academico.ufs.br \\ Ailton Fernando Santana de Oliveira \\ ORCID: https://orcid.org/0000-0003-2894-3556 \\ Universidade Federal de Sergipe, Brasil \\ E-mail: ailtonufs@gmail.com
}

\begin{abstract}
Resumo
O futebol feminino tem conquistado espaço no cenário mundial nos últimos anos, haja vista o aumento no número de praticantes, espectadores bem como o aumento de transmissão dos jogos pelos canais de TV. No Brasil, isso não é diferente, tendo o campeonato brasileiro como a principal competição da modalidade. Em se tratando de futebol o gol é o principal momento do esporte, podendo ocorrer de jogadas normais de ataque ou contra-ataque, de jogadas de bola parada ou de falhas técnicas. Nesse sentido, o objetivo desse estudo foi classificar os gols que aconteceram no campeonato brasileiro de futebol feminino em 2020, dentro das variáveis, jogadas de ataque, contra-ataque, bola parada e falhas técnicas por meio da análise dos vídeos compactos dos melhores momentos dos jogos. O estudo contou com uma amostra total de 134 jogos do campeonato brasileiro de futebol feminino de 2020 disputado por 16 clubes. A análise foi realizada por meio do método de scout. Foi possível concluir que a maioria dos gols do campeonato ocorreram em jogadas de ataque ou bola parada. $\mathrm{O}$ trabalho observou as potencialidades e as deficiências de cada equipe quanto às jogadas que dão origem aos gols.
\end{abstract}

Palavras-chave: Esportes; Futebol; Análise do desempenho; Mulheres.

\begin{abstract}
Women's football has conquered space on the world stage in recent years, given the increase in the number of players, spectators as well as the increase in the transmission of games on TV channels. In Brazil, this is no different, with the Brazilian championship as the main competition in the modality. When it comes to soccer, the goal is the main moment of the sport, and it can occur from normal attacks or counter-attack plays, from set pieces or from technical failures. In this sense, the objective of this study was to classify the goals that happened in the Brazilian women's soccer championship in 2020, within the variables, attacking plays, counterattacks, set pieces and technical failures through the analysis of compact videos of the best moments of the games. The study included a total sample of 134 games in the 2020 Brazilian women's soccer championship played by 16 clubs. The analysis was performed using the scout method. It was possible to conclude that most of the goals in the championship occurred in attack plays or set pieces. The work observed the strengths and shortcomings of each team regarding the plays that give rise to the goals.

Keywords: Sports; Soccer; Performance analysis; Women.

\section{Resumen}

El fútbol femenino ha conquistado espacio en el escenario mundial en los últimos años, tanto por el aumento de jugadoras, espectadoras como por el aumento de la transmisión de partidos en canales de televisión. En Brasil, esto no es diferente, con el campeonato brasileño como principal competencia en la modalidad. En el fútbol, el gol es el momento principal del deporte, y puede ocurrir desde ataques normales o jugadas de contraataque, desde jugadas a balón parado o por fallas técnicas. En este sentido, el objetivo de este estudio fue clasificar los goles que ocurrieron en el campeonato brasileño de fútbol femenino en 2020, dentro de las variables, jugadas de ataque, contraataques, jugadas a balón parado y fallas técnicas a través del análisis de videos compactos de los mejores momentos de Brasil. los juegos. El estudio incluyó una muestra total de 134 partidos en el campeonato brasileño de fútbol femenino 2020 disputado por 16 clubes. El análisis se realizó mediante el método scout. Se pudo concluir que la mayoría de los goles del campeonato ocurrieron en jugadas de ataque o jugadas a balón parado. El trabajo observó las fortalezas y deficiencias de cada equipo en cuanto a las jugadas que dan lugar a los goles.
\end{abstract}

Palabras clave: Deportes; Fútbol; Análisis del rendimento; Mujeres. 


\section{Introdução}

O futebol feminino tem conquistado espaço no cenário mundial nos últimos anos, com base em números da Europa que descrevem um crescimento exponencial, de acordo com as estatísticas, são mais de 29 milhões de mulheres jogando futebol ao redor do mundo, dados estes que dobraram nos últimos 10 anos (Balardin et. al., 2021). Os primeiros registros sobre o futebol feminino datam do início do século XIX na Inglaterra, mas ele teria sofrido retaliações e sua proibição pela Federação Inglesa de Futebol, que publicou uma determinação, em 1921, onde solicitava aos clubes federados que encerrassem os times femininos e proibissem partidas oficiais em seus clubes (Pessanha, 2021).

No Brasil o futebol feminino também precisou lutar contra o estigma de que era um esporte exclusivamente masculino, sendo sua prática proibida. Em abril de 1941 foi instituído o decreto-lei 3.199, que criou o Conselho Nacional de Desportos (CND) e indicou, em seu artigo 54, a não permissão de práticas desportivas incompatíveis com a natureza feminina, cabendo ao CND às instruções necessárias para tal prática (Brasil, 1941). A proibição da prática do esporte se deu com a justificativa baseada na maioria das vezes em discursos médicos, de que o esporte poderia fazer mal aos órgãos reprodutivos femininos, prejudicando assim, a eficácia do cumprimento do papel social esperado das mulheres, a maternidade (Pessanha, 2021). O CND revogou a proibição da prática do futebol por mulheres somente em 1979, havendo, no início dos anos 1980, uma reconfiguração da situação do cenário daquelas que se interessavam pelo futebol (Souza, 2019).

O início dos anos 2000 marca o ciclo vitorioso em termos de resultados da seleção brasileira e consequentemente um aumento na visibilidade do futebol feminino. Medalha de Ouro nos Jogos Pan-Americanos de Santo Domingo (2003) e do Rio de Janeiro (2007), Campeãs Sul-Americanas (2003), Medalha de Prata nos Jogos Olímpicos de Atenas (2004) e de Pequim (2008) e Vice-campeãs da Copa do Mundo de Futebol Feminino da China (2007) (Goellner, 2021). O crescimento e a profissionalização do futebol feminino também alimentaram pesquisas sobre o desenvolvimento de jogadoras e treinadoras (Sleeman \& Ronkainen, 2020). Porém, existe uma escassez de estudos analisando indicadores-chave do desempenho para mulheres sendo observadas apenas as suas capacidades físicas (Unanue, 2020).

O primeiro Campeonato Brasileiro organizado pela Confederação Brasileira de Futebol (CBF) aconteceu no ano de 2013, o critério de participação dos clubes foi estar entre os 20 primeiros colocados no Ranking Nacional de Clubes do Futebol Feminino (RNC/FF) (CBF, 2013). Já para a participação nas edições de 2014 à 2016 foram distribuídas vagas para os oito primeiros colocados no RNC/FF no ano da competição, uma vaga para a equipe campeã da Copa do Brasil de Futebol Feminino do mesmo ano e as onze vagas restantes, foram completadas pelos clubes que disputaram o Campeonato Brasileiro da Série A no ano anterior obedecendo a classificação (CBF, 2014).

Atualmente, existem, no Brasil, duas ligas de futebol feminino a Série A1 e a Série A2 do Campeonato Brasileiro. Ambas as séries são organizadas pela CBF, sendo que a Série A1 em 2020 teve sua oitava edição e a A2 sua quarta. Além do Campeonato Brasileiro, a CBF também tem como competições oficiais no calendário anual a Copa do Brasil e alguns campeonatos estaduais (CBF, 2020). Contudo, o investimento no futebol de base feminino vem crescendo nos últimos anos, atualmente a CBF promove os Campeonato Brasileiro sub-18 com sua primeira edição no ano de 2019 com 24 clubes participantes (CBF, 2019) e o Campeonato Brasileiro sub-16 com sua primeira edição também no ano de 2019 com 12 clubes participantes (CBF, 2019a).

As evidências empíricas sugerem que as variáveis situacionais do local da partida (ou seja, jogar em casa ou fora), o status da partida (ou seja, se a equipe estava ganhando, perdendo ou empatando) e a qualidade da oposição (forte ou fraca) são fatores muito importantes para performances de futebol (Lago, 2012). De acordo com estudo realizado por Silveira e Flôres (2018), do Campeonato Brasileiro de Futebol Feminino no ano de 2017, em que foram analisadas as variáveis dos gols em jogadas de ataque e contra-ataque, de bolas paradas, por falha das goleiras, gols contra, pênaltis e jogadas de escanteios, os autores concluem que $70,91 \%$ dos gols ocorreram em situações de ataque ou contra-ataque, 10,10\% em cobranças de pênalti, 
observando também a ineficácia das equipes de futebol feminino quanto aos lances de bola parada apresentando índices de acerto de $1,44 \%$.

O gol é o objetivo principal do futebol, caracterizado pelo ato da bola ultrapassar completamente a linha entre as traves ou baliza da equipe adversária (Kunzel, 2018). Assim, segundo De Jong et. al. (2020), a ação técnica mais importante para vencer uma partida no futebol feminino é marcar o primeiro gol. Führer (2014), completa afirmando que o gol é o momento mais importante do jogo, por isso evidencia a necessidade da realização de estudos com este objetivo. Ao possibilitar uma análise técnica e tática sobre os esquemas táticos de ataque das equipes do futebol feminino será possível avançar no seu treinamento e entendimento dos pontos chaves que viabilização a marcação de gols durante uma partida. No Brasil estudos sob esta perspectiva se mostram escassos.

Nesse sentido, o estudo tem como objetivo identificar os gols marcados no campeonato brasileiro de futebol feminino em 2020, a partir de uma análise de prevalência (jogadas de ataque, contra-ataque, bola parada e falhas técnicas tipos de gols de cada) e análise de desempenho das equipes (total de gols da primeira fase do campeonato e fase final).

\section{Metodologia}

Esse estudo foi conduzido por meio da análise de prevalência dos jogos do campeonato brasileiro de futebol feminino 2020. A coleta de dados foi realizada por um avaliador e se deu através do acesso ao canal Brasileirão Feminino que dispõe dos vídeos compactos dos melhores momentos de todas as partidas do campeonato.

A amostra do estudo foi composta por todos os 134 jogos do campeonato brasileiro de futebol feminino 2020. O campeonato foi disputado em duas fases: classificatória (pontos corridos) e eliminatória (quartas de finais, semifinal e final). A primeira fase foi composta por 16 clubes, em um grupo com todos os clubes jogando entre eles, totalizando 120 partidas. Na segunda fase as oito melhores equipes se classificam para a fase quartas de final. Da mesma forma, os vencedores passam para a semifinal e as duas equipes vencedoras disputaram a final. As 14 partidas da fase eliminatória, conhecido pelo formato de "mata-mata" foram analisadas em conjunto, à parte da fase classificatória.

\subsection{Prevalência}

Foi utilizado o método de scout que tem por objetivo avaliar por meio de dados quantitativos o desempenho das equipes em treinamentos e durante partidas oficiais (Neves et. al., 2020). Essa análise se deu por meio da análise dos vídeos compactos dos melhores momentos dos jogos, que são lances selecionados sempre que a possibilidade de gol. Para fins deste estudo foram analisados apenas os lances que resultaram em gols, anotando sua prevalência a partir dos respectivos momentos (Figura 1):

Figura 1. prevalência dos momentos que resultaram em gol nos jogos analisados do campeonato brasileiro feminino de futebol.

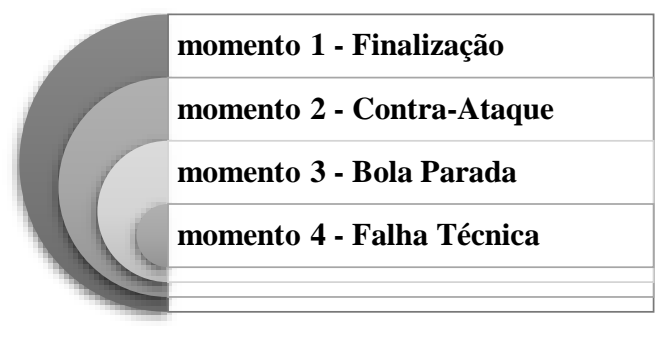

Fonte: Autores.

O primeiro momento é caracterizado por jogadas normais de ataque que resultaram na construção de um lance onde a equipe detentora da posse de bola confronta uma defesa organizada, da qual a finalização resultou em gol. O segundo, é originado 
por jogadas de contra-ataque provenientes da retomada da bola de forma que a defesa adversária estivesse desorganizada, cuja finalização originou o gol. O terceiro momento ocorreu com jogadas de bola parada (escanteios, faltas e pênaltis) e foram consideradas como origem do gol quando ocorreu finalização direta ou passe para finalização, nos casos em que ocorreram rebatida, a bola deve ter sido finalizada em gol novamente ou ocorreu passe para a finalização, resultando em gol. E por fim, o quarto momento é decorrente de falhas técnicas (das goleiras e gol contra), falhas como, deixar a bola escapar das mãos ou pés, passe direto para o adversário que tenha originado o gol adversário, ou quando a jogadora de uma das equipes faz o gol em sua própria meta (gol contra), havendo combinação das demais categorias com a falha técnica. É considerado falha técnica quando esta foi o principal motivo do gol.

\subsection{Análise dos dados}

Foi estabelecida uma análise descritiva através de valores percentuais em relação aos gols para um posterior ranqueamento das melhores equipes a partir dos momentos de prevalência estabelecidos de acordo com as fases da competição (classificatória e eliminatória). Nos casos de dúvida em relação aos momentos de prevalência do gol (momento 1, 2, 3 ou 4), foi solicitada a opinião de um segundo avaliador para a tomada de decisão.

\section{Resultados e Discussão}

A Tabela 1 apresenta a origem dos gols durante a primeira fase da competição (classificatória), assim como saldo de gols na primeira fase do campeonato (395), sendo que o maior número de gols feitos teve sua origem em jogadas de ataque, representando um total de 44,6\% dos gols, seguidas de ações de contra-ataque $(15,7 \%)$.

Tabela 1. Origem dos gols da primeira fase da competição de acordo com os momentos de prevalência.

\begin{tabular}{lc}
\hline Jogadas de Ataque - momento 1 & $44,6 \%(176)$ \\
Contra-Ataque - momento 2 & $15,7 \%(62)$ \\
Bola Parada - momento 3 & $27,8 \%(110)$ \\
Falha Técnica - momento 4 & $11,9 \%(47)$ \\
\hline Total de gols & $100 \%(395)$ \\
\hline
\end{tabular}

Fonte: Autores.

Os gols que foram feitos de bola parada, representam 27,8\%, com um total de 110 gols, sendo eles distribuídos em escanteios com 35,5\% dos gols, faltas com 33,6\% e pênaltis representando 30,9\%. O menor número de gols feitos foi por falhas técnicas com 47 (11,9\%) gols, distribuídos em falhas das goleiras 76,6\% e em gol contra 23,4\%.

Os resultados encontrados se assemelham ao estudo de Silveira e Flôres (2018) com um maior aproveitamento em jogadas de ataque durante o Campeonato Brasileiro de Futebol Feminino no ano de 2017. As variáveis contra-ataque e falhas técnicas tiveram o menor índice de gols, diferente do estudo feito por Bezerra e Navarro (2012) em pesquisa realizada com o futsal feminino, em que o maior índice de gols se deu por meio do contra-ataque. Assim, como observado por Abreu et. al., (2021), 66.7\% dos gols no futebol feminino são decorrentes da bola em jogo, ou seja, seguidos de roubadas de bola no campo ofensivo e defensivo.

Na Tabela 2 é possível perceber durante a primeira fase da competição os momentos de prevalência dos gols marcados por cada equipe. Dos gols feitos em jogadas de ataque, 15,3\% deles foram feitos pelo Corinthians, o Avaí-Kindermann fez 10,2\% dos gols, São Paulo e Santos marcaram 9,1\% dos gols. Já os marcados por contra-ataque o Corinthians fez 12,9\%, o São José marcou 11,2\%, São Paulo e Ferroviária marcaram 9,7\% dos gols. Dos 110 gols feitos de bola parada o Avaí-Kindermann marcou 
12,7\%, o Internacional marcou 10,9\% e o Flamengo 10,0\% dos gols. Já os que tiveram origem por falhas técnicas o Internacional foi beneficiado com um total de 19,1\%, seguido do Santos e do Iranduba com 10,6\% dos gols marcados.

Tabela 2. percentual de gols marcados por cada equipe em relação ao total de cada variável na primeira fase do campeonato

\begin{tabular}{lcccc}
\hline \multicolumn{1}{c}{ Times } & Jogadas de Ataque & Contra-Ataque & Bola Parada & Falha Técnica \\
\hline Corinthians & $15,3 \%$ & $12,9 \%$ & $7,3 \%$ & $4,3 \%$ \\
Santos & $9,1 \%$ & $6,5 \%$ & $9,1 \%$ & $10,6 \%$ \\
Internacional & $8,5 \%$ & $4,8 \%$ & $10,9 \%$ & $19,1 \%$ \\
Ferroviária & $8,5 \%$ & $9,7 \%$ & $9,1 \%$ & $6,4 \%$ \\
Palmeiras & $8,0 \%$ & $8,1 \%$ & $8,2 \%$ & $8,5 \%$ \\
Avaí-Kindermann & $10,2 \%$ & $6,5 \%$ & $12,7 \%$ & $6,4 \%$ \\
São Paulo & $9,1 \%$ & $9,7 \%$ & $6,4 \%$ & $8,5 \%$ \\
Grêmio & $2,8 \%$ & $3,2 \%$ & $6,4 \%$ & $6,4 \%$ \\
Flamengo & $2,8 \%$ & $8,1 \%$ & $10,0 \%$ & $4,3 \%$ \\
Cruzeiro & $6,3 \%$ & $6,5 \%$ & $7,3 \%$ & $2,1 \%$ \\
São José & $6,8 \%$ & $11,2 \%$ & $2,7 \%$ & $4,3 \%$ \\
Minas Brasília & $7,4 \%$ & $1,6 \%$ & $3,6 \%$ & $6,4 \%$ \\
Iranduba & $4,0 \%$ & $1,6 \%$ & $2,7 \%$ & $10,6 \%$ \\
Ponte Preta & $0,0 \%$ & $4,8 \%$ & $3,6 \%$ & $0,0 \%$ \\
Audax & $0,6 \%$ & $3,2 \%$ & $0,0 \%$ & $2,1 \%$ \\
Vitória & $0,6 \%$ & $1,6 \%$ & $0,0 \%$ & $0,0 \%$ \\
\hline Total de gols & $176(100 \%)$ & $62(100 \%)$ & $110(100 \%)$ & $47(100 \%)$ \\
\hline
\end{tabular}

Fonte: Autores.

Observando o total de gols marcados por todas as equipes na primeira fase do campeonato, a equipe que se destacou teve uma maior prevalência de gols em dois momentos: jogadas de ataque e contra-ataque. A equipe que teve a melhor prevalência em jogadas de bola parada foi a segunda melhor em jogadas de ataque. Barletta (2009), destaca a defesa e o ataque como estruturas fundamentais para qualquer equipe de alto rendimento. Já com relação às jogadas de bola parada, os dados obtidos por Bueno (2007) expõem uma importância crescente desse tipo de ação como forma de desencadear chances de gol, levando assim a equipe a um melhor desempenho na competição.

A Tabela 3 traz as informações dos gols feitos pelas equipes. A equipe que fez a maior quantidade de gols foi o Corinthians com um saldo de 45 gols, sendo eles distribuídos da seguinte forma: jogadas de ataque (60,0\%), contra-ataque $(17,8 \%)$, bola parada $(17,8 \%)$ e em falhas técnicas $(4,4 \%)$. O segundo melhor desempenho foi do Internacional com um saldo 39 gols, sendo o que maior percentual de gols feitos foram por jogadas de ataques. A equipe que obteve o pior desempenho foi o Vitória, tendo marcado apenas 2 gols durante o campeonato, desse total um gol foi feito por uma jogada de ataque e o outro por contra-ataque. 
Tabela 3. Percentual de gols marcados em cada categoria em relação ao total de gols da equipe.

\begin{tabular}{lcccccc}
\hline Times & Jogadas de Ataque & Contra-Ataque & Bola Parada & Falha Técnica & Total de gols & Percentual total \\
\hline Corinthians & $60,0 \%$ & $17,8 \%$ & $17,8 \%$ & $4,4 \%$ & 45 & $100 \%$ \\
Santos & $45,7 \%$ & $11,4 \%$ & $28,6 \%$ & $14,3 \%$ & 35 & $100 \%$ \\
Internacional & $38,4 \%$ & $7,7 \%$ & $30,8 \%$ & $23,1 \%$ & 39 & $100 \%$ \\
Ferroviária & $44,1 \%$ & $17,6 \%$ & $29,4 \%$ & $8,9 \%$ & 34 & $100 \%$ \\
Palmeiras & $43,8 \%$ & $15,6 \%$ & $28,1 \%$ & $12,5 \%$ & 32 & $100 \%$ \\
Avaí-Kindermann & $46,2 \%$ & $10,3 \%$ & $35,8 \%$ & $7,7 \%$ & 39 & $100 \%$ \\
São Paulo & $48,5 \%$ & $18,2 \%$ & $21,2 \%$ & $12,1 \%$ & 33 & $100 \%$ \\
Grêmio & $29,4 \%$ & $11,8 \%$ & $41,2 \%$ & $17,6 \%$ & 17 & $100 \%$ \\
Flamengo & $21,7 \%$ & $21,7 \%$ & $47,8 \%$ & $8,8 \%$ & 23 & $100 \%$ \\
Cruzeiro & $45,8 \%$ & $16,7 \%$ & $33,3 \%$ & $4,2 \%$ & 24 & $100 \%$ \\
São José & $50,0 \%$ & $29,2 \%$ & $12,5 \%$ & $8,3 \%$ & 24 & $100 \%$ \\
Minas Brasília & $61,9 \%$ & $4,8 \%$ & $19,0 \%$ & $14,3 \%$ & 21 & $100 \%$ \\
Iranduba & $43,7 \%$ & $6,3 \%$ & $18,7 \%$ & $31,3 \%$ & 16 & $100 \%$ \\
Ponte Preta & $0,0 \%$ & $42,9 \%$ & $57,1 \%$ & $0,0 \%$ & 7 & $100 \%$ \\
Audax & $25,0 \%$ & $50,0 \%$ & $0,0 \%$ & $25,0 \%$ & 4 & $100 \%$ \\
Vitória & $50,0 \%$ & $50,0 \%$ & $0,0 \%$ & $0,0 \%$ & 2 & $100 \%$ \\
\hline
\end{tabular}

Fonte: Autores.

A fase final do campeonato por ter um quantitativo menor de partidas (um total de 14 partidas) teve um menor número de gols (um total de 33 gols). Como aconteceu na primeira fase, o maior quantitativo de gols se deu por jogadas de ataque $(45,5 \%)$, logo depois bola parada (30,3\%), sendo que a maior quantidade de gols feitos por bola parada foi de escanteios $70,0 \%$. O número de gols feitos em falhas técnicas representa 15,1\%, desses gols, 80,0\% foi por falha das goleiras e $20 \%$ por gol contra. E os que têm origem no contra-ataque representam $9,1 \%$ do total dos gols feitos.

Do total dos gols feitos por jogadas de ataque, 33,33\% quem fez foi a equipe do Corinthians, seguido do AvaíKindermann com 26,6\%. Dos que tiveram origem por falha técnica, o Corinthians foi beneficiado com 60,0\% deles, seguido do Avaí-Kindermann (20,0\%) e do Internacional (20,0\%), segundo a Tabela 4. Dentre os times que ficaram entre os 8 primeiros colocados, o Santos foi o que obteve o pior resultado, não fazendo nenhum gol na fase final.

Tabela 4. Percentual de gols marcados por cada equipe em relação ao total de cada variável na fase final do campeonato.

\begin{tabular}{lcccc}
\hline Times & Jogadas de Ataque & Contra-Ataque & Bola Parada & Falha Técnica \\
\hline Corinthians & $33,3 \%$ & $33,3 \%$ & $30,0 \%$ & $60,0 \%$ \\
Avaí-Kindermann & $26,6 \%$ & $33,3 \%$ & $30,0 \%$ & $20,0 \%$ \\
São Paulo & $20,0 \%$ & $0,0 \%$ & $10,0 \%$ & $0,0 \%$ \\
Palmeiras & $6,7 \%$ & $0,0 \%$ & $10,0 \%$ & $0,0 \%$ \\
Santos & $0,0 \%$ & $0,0 \%$ & $0,0 \%$ & $0,0 \%$ \\
Internacional & $6,7 \%$ & $0,0 \%$ & $10,0 \%$ & $20,0 \%$ \\
Ferroviária & $0,0 \%$ & $33,3 \%$ & $10,0 \%$ & $0,0 \%$ \\
Grêmio & $6,7 \%$ & $0,0 \%$ & $0,0 \%$ & $0,0 \%$ \\
\hline Percentual total & $100 \%$ & $100 \%$ & $100 \%$ & $100 \%$ \\
\hline
\end{tabular}

Fonte: Autores.

O Corinthians foi a equipe que teve o melhor desempenho na fase final, com um total de 12 gols, com 41,7\% dos gols marcados tendo sua origem em jogadas de ataque, logo depois por bola parada e falhas técnicas com $25,0 \%$ em ambos. O segundo 
melhor desempenho foi da equipe do Avaí-Kindermann totalizando 9 gols, como a equipe anterior, a origem dos gols foi por jogadas de ataque. A equipe que fez mais gols em jogadas de ataque foi o São Paulo (75,0\%), ver Tabela 5.

Tabela 5. Percentual de gols marcados em cada categoria em relação ao total de gols da equipe.

\begin{tabular}{lcccccc}
\hline Times & Jogadas de Ataque & Contra-Ataque & Bola Parada & Falha Técnica & Total de gols & Percentual Total \\
\hline Corinthians & $41,7 \%$ & $8,3 \%$ & $25,0 \%$ & $25,0 \%$ & 12 & $100 \%$ \\
Avaí- Kindermann & $44,5 \%$ & $11,1 \%$ & $33,3 \%$ & $11,1 \%$ & 9 & $100 \%$ \\
São Paulo & $75,0 \%$ & $0,0 \%$ & $25,0 \%$ & $0,0 \%$ & 4 & $100 \%$ \\
Palmeiras & $50,0 \%$ & $0,0 \%$ & $50,0 \%$ & $0,0 \%$ & 2 & $100 \%$ \\
Santos & $0,0 \%$ & $0,0 \%$ & $0,0 \%$ & $0,0 \%$ & 0 & $100 \%$ \\
Internacional & $33,3 \%$ & $0,0 \%$ & $33,3 \%$ & $33,3 \%$ & 3 & $100 \%$ \\
Ferroviária & $0,0 \%$ & $50,0 \%$ & $50,0 \%$ & $0,0 \%$ & 2 & $100 \%$ \\
Grêmio & $100,0 \%$ & $0,0 \%$ & $0,0 \%$ & $0,0 \%$ & 1 & $100 \%$ \\
\hline
\end{tabular}

Fonte: Autores.

Analisando toda a competição, fase classificatória e fase eliminatória, é possível observar no estudo o momento de prevalência de gols em jogadas de ataque e um percentual menor de gols realizados por meio do contra-ataque e falhas técnicas. A literatura corrobora com os dados encontrados nesta pesquisa em relação ao momento de prevalência de gols estar centrado nas jogadas de ataque (Araya \& Larkin, 2013; Anderson \& Sally, 2013; Silveira \& Flôres, 2018).

\section{Conclusão}

Foi possível concluir com esse estudo que a maioria dos gols na fase classificatória do campeonato foram realizados em momentos de prevalência em jogadas de ataque ou bola parada. Os diferentes tipos de bola parada tiveram percentuais semelhantes. As duas equipes finalistas contribuíram com mais de 10,0\% dos gols em pelo menos dois momentos de prevalência de gols na fase classificatória.

$\mathrm{Na}$ fase eliminatória o maior percentual de gols foi em jogadas de ataque, assim como na fase classificatória. Os momentos de prevalência para jogadas de bola parada tiveram um percentual alto sendo 70,0\% por meio do escanteio. A soma de todos os momentos de prevalência no ataque e bola parada são responsáveis por mais de 70,0\% dos gols no campeonato como um todo. As duas equipes finalistas foram responsáveis por mais de 60,0\% dos gols em todos momentos de prevalência na fase eliminatória da competição.

Enquanto limitações do estudo seriam necessários o uso de outros instrumentos para avaliar as formas de gols dentro do futebol feminino, além disso seria necessária a inclusão de outras variáveis que não foram exploradas neste estudo, como, ser o mandante ou o visitante da partida, tempo de incidência dos gols durante a partida e zonas do campo onde ocorrem mais gols.

Diante dos resultados obtidos, é de grande importância que sejam realizadas novas pesquisas com essa temática, pois esse trabalho leva a observar as potencialidades e as deficiências de cada equipe durante os momentos de prevalência em jogadas de ataque, contra-ataque, bola parada e falhas técnicas. A carência de estudos no futebol feminino brasileiro, ressalta a importância de formar uma massa crítica que irá instrumentalizar treinadores para aperfeiçoar seus sistemas de treinamento, elevando desta forma o nível das equipes e consequentemente o futebol feminino brasileiro como um todo.

\section{Referências}

Abreu, F. F., Gaspar, R. C. \& Pauli, J. R. (2021). Comparação analítica dos ataques resultantes em gol das equipes sub-17 masculina e sub-18 feminina do flamengo no campeonato brasileiro de futebol. RBFF - Revista Brasileira de Futsal e Futebol, 12(51), 646-654.

Anderson, C., \& Sally, D. (2013). Os números do jogo: porque tudo que você sabe sobre o futebol está errado. Paralela. 
Araya, J. A., \& Larkin, P. (2013). Key performance variables between the top 10 and bottom 10 teams in the English Premier League 2012/2013 season. The University of Sydney.

Balardin, G. F., Voser, R. da C., Duarte, M. A., \& Mazo, J. Z. (2018). O futebol feminino no Brasil e nos Estados Unidos: semelhanças e diferenças no esporte. RBFF - Revista Brasileira de Futsal e Futebol, 10(36), 101-109.

Barletta, F. G. (2009). Análise da origem, ocorrência e execução dos gols no futebol. Lecturas: Educación Física y Deportes, 14(132).

Bezerra, R. B. \& Navarro, A. C. (2012). Análise dos gols da VI Taça Brasil de Clubes 2010 na categoria sub-20 feminino. RBFF - Revista Brasileira de Futsal e Futebol, 4(11).

Brasil. (1941). Decreto-lei no 3.199, de 14 de abril de 1941. Estabelece as bases de organização dos desportos em todo o país. Diário Oficial da União. <http://www.planalto.gov.br/ccivil_03/decreto-lei/1937-1946/del3199.htm>.

Bueno, R. L. (2007). Análise das táticas do grupo ofensivo das equipes participantes do campeonato mundial de futebol de 2006 na Alemanha. Lecturas: Educación Física y Deportes, 12(114).

Confederação Brasileira De Futebol. (2013). Campeonato Brasileira de Futebol Feminino Terá 1a edição em 2013. <Https://Www.Cbf.Com.Br/FutebolBrasileiro/Noticias/Campeonato-Brasileiro-Feminino/Campeonato-Brasileiro-De-Futebol-Feminino-Tera-1a-Edicao-Em-2013>.

Confederação Brasileira De Futebol. (2014). Campeonato brasileiro de futebol feminino de 2014 rec - regulamento específico da competição. <https://conteudo.cbf.com.br/cdn/201409/20140903165134_0.pdf.

Confederação Brasileira De Futebol. (2019). Regulamento Específico da Competição Campeonato Brasileiro Sub-18 de Futebol Feminino 2019. Rio de Janeiro, 2019c. https://conteudo.cbf.com.br/cdn/201907/20190705124607_65.pdf.

Confederação Brasileira De Futebol. (2019a). Regulamento Específico da Competição Campeonato Brasileiro Sub-16 de Futebol Feminino 2019. Rio de Janeiro, 2019b. https://conteudo.cbf.com.br/cdn/201911/20191125120844_184.pdf

Confederação Brasileira De Futebol. (2020). Regulamento Específico da Competição Campeonato Brasileiro Feminino A-1 2020. Rio de Janeiro, 2020. https://conteudo.cbf.com.br/cdn/202008/20200821164718_261.pdf.

De Jong, L. M. S. Gastin, P. B., Angelova, M., Bruce, L., \& Dwyer, D. B. (2020). Technical determinants of success in professional women's soccer: A wider range of variables reveals new insights. PLoS One, 15(10), e0240992.

Führer, F. D. (2014). Futebol: Análise descritiva de gols do campeonato brasileiro de 2013 - Série A. Trabalho de conclusão de curso. Universidade Federal do Rio Grande do Sul, Escola de Educação Física.

Goellner, S. V. (2021). Mulheres e futebol no brasil: descontinuidades, resistência e resiliência. Revista de Educação Física da UFRGS, 27. https://www.scielo.br/j/mov/a/BL3dbSMQpV3KyFcsqhWyQVc/?format=pdf\&lang=pt

Kunzel, R., Crescente, L. B., Siqueira, O. D., \& Garlipp, D. C. (2018). Análise dos gols marcados no futebol de campo masculino dos Jogos Olímpicos de 2016. Revista Brasileira De Futsal E Futebol, 10(37), 157-163.

Lago, P. C. (2012). The Role of Situational Variables in Analysing Physical Performance in Soccer. J Hum Kinet, 35. 89-95.

Neves, A. A., Sousa, G. R., Corrêa, H. L., \& Mazzoccante, R. P. (2020). Análise de scout em jogos da Copa do Mundo de 2018: fundamentos técnicos da posse de bola e finalizações na fase de grupos e eliminatórias. RBFF - Revista Brasileira De Futsal e Futebol, 12(47), 10-16.

Pessanha, N. F. (2021). O mundo da bola. A proibição do futebol de mulheres em diferentes campos. Rev. Esporte e Sociedade. 13(32).

Silveira, T. C. W., \& Flôres, F. S. (2018). Análise dos gols sofridos no campeonato brasileiro feminino de futebol. Revista Brasileira de Futebol e Futsal, 10(37), 202-208.

Sleeman, E. J., \& Ronkainen, N. J. (2020). The Professionalization of Women's Football in England and its Impact on Coaches' Philosophy of Practice. International Sport Coaching Journal, 7, 326-334.

Souza, L. M., Maux, A. A. B., \& Rebouças, M. S. S. Impedimento? Possibilidades de relação entre a mulher e o futebol. Rev. abordagem Gestalt. Goiânia, 25(3), 282-293.

Unanue, J. G., Luna, A. F., Burillo, P., Gallardo, L., Sanchez, J. S., Carrasco, S. M., \& Felipe, J. L. (2020). Key performance indicators at FIFA Women's World Cup in different playing surfaces. PLOS ONE 15(10): e241385. 